\title{
Violência no lar contra a criança
}

\author{
Gilberto Pascolat
}

\section{RESUMO}

\begin{abstract}
A violência doméstica contra a criança refere-se a uma gama de situações que envolvem a criança, desde a negligência até os maus tratos de ordem física e de abuso sexual. A etiologia da violência familiar é multifatorial e sua compreensão exige a observação das circunstâncias e do ambiente em que a criança vive. Esse tipo de violência é universal, envolve meninos e meninas e refere-se a uma histórica violência contra a mulher nas relações conjugais. Este artigo, além de apresentar conceitos básicos relativos ao tema, procura orientar procedimentos para a detecção do problema - tanto pela anamnese como pelo exame físico, tecendo considerações também a respeito do diagnóstico e da denúncia - e chama a atenção para um tipo de violência muitas vezes esquecida, a violência emocional.

Palavras-chave: violência familiar, negligência, abuso sexual.
\end{abstract}

\begin{abstract}
Domestic children abuse is due to some situations which involve negligence and sexual and physical abuse. The ethiology of familiar violence has many factors and in order to understand it, one must observe children's environment. This kind of violence is universal, involving boys and girls, and this refers to historical violence against women and spouses'relationship.This paper not only presents basic concepts but also tries to present ways of preventing the problem - by means of anamnesis and physical examination; it also considers some diagnosis and accusations - and attention to emotional violence, which is many times underestimated, is given.

Key-words: familiar violence, negligence, sexual abuse.
\end{abstract}

\section{Introdução}

O termo violência familiar engloba negligência e maus tratos com a criança e violência no casamento. A etiologia multifatorial dos maus tratos contra a criança exige que se leve em consideração as circunstâncias e o ambiente em que ela vive. Portanto, tantos os pontos fortes como os problemas individuais, os pontos de apoio, os agentes causadores de estresse e as características da família e da vizinhança são pertinentes.

\section{Epidemiologia}

Nos EUA (1994), 3\% dos pais declararam usar violência grave (soco, queimaduras, armas de fogo e armas brancas) contra os seus filhos. Estudos sugerem que 1 em cada 3 meninas e 1 em cada 6 meninos sofreram abusos sexuais (EUA). Quase três milhões de queixas de maus tratos contra crianças foram registradas em 1993, metade por negligência. A pobreza está associada à violência familiar. A violência contra a mulher é universal (25\% dos casais americanos passam por episódios de violência conjugal). $75 \%$ das mulheres maltratadas denunciam que seus filhos também o foram. O simples fato de testemunhar a violência pode ser muito nocivo. Elas podem culpar-se por ser a causa da violência. Há uma grande tendência para que a criança que foi testemunha de violência entre os pais de se tornar um homem que maltrate a família.

\section{Etiologia da violência familiar}

Não existe uma causa única da violência contra a criança. O temperamento difícil da criança ou a falta de firmeza dos pais pode aumentar os riscos de maus-tratos. A violência conjugal, o abandono do pai, a falta 
de apoio social, os agentes causadores de estresse, como bairros perigosos ou isolamento social, a aceitação ampla da punição (castigo corporal) e o estimulo à violência nos filmes e na música, provocam situações de risco para a criança.

\section{Detecção da violência na família}

Realizar perguntas relativas ao bem-estar dos pais, o sentimento deles em relação à criança, problemas com a criança e como os pais lidam com eles, relacionamento conjugal, o envolvimento do pai na assistência à criança, pontos de apoio e de tensão e mudanças recentes na vida familiar. É importante avaliar diretamente a maneira como a criança percebe a sua situação e o seu bem-estar.

Perguntas a serem feitas para a criança:

- Como estão as coisas na escola, em casa, no bairro?

- Quem vive com você?

- Como é o seu relacionamento com as pessoas da sua casa?

- Que tipo de atividades você faz com elas?

- Existe algo que você gostaria de mudar?

- O que faz quando alguma coisa o incomoda?

- As pessoas brigam na sua casa? De que maneira? A respeito de quê?

Perguntas para os pais:

- Como vocês estão?

- Vocês se preocupam com

- O que você faria se

- Quem os ajuda com as crianças?

- Vocês têm tempo para se dedicarem a si mesmos?

- O que acham do bairro onde moram?

- Como era o seu relacionamento com o pai de

- A violência e as drogas são problemas graves atualmente?

- Há algum tipo de violência ou desavença em casa?

- Alguém usa drogas em casa?

A observação direta dos pais da criança e do seu relacionamento pode revelar informações úteis. O pai está preocupado com o bem estar do filho? A criança parece ter medo do pai e estar relutante em falar? O relacionamento entre os familiares parece caloroso e tranqüilo ou há tensão e raiva? O pai bate na criança?

A anamnese e um exame profundo e cuidadoso são necessários, juntamente com a informação psicossocial completa. Para se aprender mais sobre uma família é necessário ouvir com atenção e sugerir que os pais contem histórias importantes ("Como foi a sua infância?" "Qual o seu objetivo como pai?").

Consultas mais freqüentes podem ser marcadas. $\mathrm{O}$ apoio e aconselhamento adicionais podem incluir: rever com os pais as circunstâncias difíceis que podem vir a acontecer; identificar os pontos fortes e esforços dos pais; ajudar o pai a resolver problemas; permitir ou facilitar outros recursos e comunicar o seu interesse e a sua disponibilidade para ajudar. Outros familiares importantes podem ser convidados a ajudar.

\section{Diagnóstico}

1) Indícios sugestivos: a mãe com um olho machucado, a criança com notas baixas na escola ou que sofre de enurese.

2) As descobertas físicas sozinhas raramente indicam violência. Fazer anamnese cuidadosa das circunstâncias que envolvem os sinais e sintomas para avaliar as explicações e a possível causa da violência.

3) A violência familiar não deve ser vista como diagnóstica, mas sim como sintoma de problemas subjacentes.

4) Levar em consideração explicações alternativas. 
5) As vitimas de violência conjugal podem apresentar uma variedade de lesões, incluindo-se lesões repetidas, múltiplas e sofridas durante a gravidez.

\section{Denúncia}

Os pediatras são obrigados por lei a denunciar aos organismos responsáveis pela proteção adequada do menor, o diagnóstico ou suspeita de possível abuso ou negligência contra a criança. Os pediatras devem informar as famílias diretamente sobre a denúncia que será feita, de maneira delicada e compreensiva. Devese explicar que se trata de um esforço para esclarecer a situação e obter ajuda para a criança e sua família.

\section{Evidências na anamnese}

1. A história é compatível com o tipo ou grau de ferimento.

2. A história de como o ferimento ocorreu é vaga ou o pai não tem idéia de como ele ocorreu.

3. A história muda cada vez que é contada a um interlocutor diferente.

4. Os pais, entrevistados separadamente, dão histórias contraditórias.

5. A história não é digna de crédito.

6. Demora significativa entre a época do ferimento e a época da consulta. criança.

7. O pai ou a mãe não demonstra o grau de preocupação apropriado à gravidade do ferimento da

8. Interação pais-criança patológica.

9. História de consultas repetidas devido a acidentes ou ferimentos.

10. História de fraturas repetidas.

11. História de intoxicações repetidas.

\section{Exame físico}

- aspecto geral (higiene, roupas)

- pele: as manifestações cutâneas de abuso são variadas e o diagnóstico diferencial deste achado é amplo. Equimoses, queimaduras, lacerações e mordidas constituem a maioria das lesões. Várias equimoses ou em regiões raramente lesadas acidentalmente (lobo da orelha, pescoço, lábio superior) ou sobre nádegas, face e genitália, são preocupantes. O reconhecimento de objetos produtores de lesão (cintos, cabides) ou do uso da mão (tapa, aperto) é muito suspeito de abuso. São sugestivas de queimaduras não acidentais as em forma de luva ou meia, as simétricas e as que apresentarem marcas nítidas do objeto usado.

- ossos: a evidencia de múltiplas fraturas deve despertar significativa preocupação. São características de abuso as fraturas em "alça de balde" nas epífises de ossos longos. As fraturas umerais e de tíbia, em lactentes e as de fêmur, em menores de 3 anos, são muito sugestivas de abuso.

- trauma abdominal: vem logo após os traumas de cabeça como causa de mortalidade em crianças abusadas. Não é facilmente detectado pela história confusa e pela escassez de sinais externos ao exame físico. A presença de choque inexplicado, peritonite, vômitos biliosos ou anemia deve despertar uma alta suspeita de abuso.

- trauma craniano: relacionado com maior morbidez e mortalidade. Fraturas múltiplas ou complexas, lesão de mais de um osso craniano, fraturas não lineares e fraturas com afundamento causam sérias preocupações. A presença de hemorragia de retina deve se tornar altamente suspeita de abuso, já que é rara em acidentes. A síndrome do bebê sacudido ocorre quando uma criança é sacudida ante o choro continuo ou comportamento irritável e pode causar hemorragia de retina, hemorragia subdural, sem sinais externos de traumatismos. 


\section{Considerações}

O abuso físico é, geralmente, repetitivo e sua severidade tende a aumentar a cada nova investida.

Qualquer lesão suspeita deve ser adequadamente investigada, considerando-se a incerteza quanto à possibilidade de acontecer uma nova chance de intervenção, além da prevenção contra conseqüências mais graves.

Ao se abordar uma criança, deve-se reconhecer que os pais são os únicos que ela conhece, que ela ama e que possa se sentir, de certo modo, merecedora do abuso.

$\mathrm{Na}$ entrevista, estabelecer uma relação com a família, explicar o caso e processo de proteção de maneira honesta.

Nenhuma atitude preconceituosa deve ser assumida diante dessas pessoas.

Os maus tratos à criança são um sintoma de disfunção familiar e não um diagnóstico. A meta da prevenção é sinônimo de apoio e fortalecimento das famílias para capacitá-las a cuidar de seus filhos mais adequadamente.

\section{Abuso sexual}

Definição

Envolvimento de uma criança em atividades sexuais que a criança não entende, não pode dar consentimento consciente ou que violam os tabus sociais.

Não é preciso haver contato sexual, nem a criança precisa ter consciência de que está sendo violentada.

Estudos sugerem que 30 a $37 \%$ são os pais, tutores ou parentes próximos, 26 a $60 \%$ são conhecidos não parentes e 11 a $37 \%$ são estranhos.

Quando o agressor é um membro da família ou conhecido, o encontro geralmente não é violento, sendo usados persuasão, suborno ou ameaças.

As manifestações iniciais são muito variadas e vão desde alterações sutis do comportamento até lesão genital evidente. Quando a criança conhece ou se interessa por comportamentos sexuais que estão além do estágio de desenvolvimento esperado para ela, há motivos para preocupação.

\section{Entrevista com a criança}

Evitar repetir a entrevista. O ideal é fazê-la imediatamente, anotando tudo. Perguntar onde mora, quem toma conta, distúrbios do sono, escola, o que faz para se divertir, partes do corpo, diferença entre bom e mau e toque, se alguém a tocou de forma ruim ou desagradável.

\section{Exame físico}

Exame geral para observar traumatismos prévios ou simultâneos como marcas de aperto, equimoses, mordidas ou trauma de faringe. O exame genital na maioria das vezes é normal. Quando alterado é suficiente para se confirmar o abuso. O exame genital requer o conhecimento da anatomia pré-puberal, ambiente tranqüilo e paciência. O hímen deve ser examinado. Não realizar exame especular.

Determinar se há suspeita razoável de abuso é obrigação do clínico. A determinação final do abuso é da alçada do sistema legal. 


\section{Abuso passivo ou negligência}

"A negligência da negligência"

Milhões de crianças jamais terminam a escola, não sabem ler, têm limitado acesso aos cuidados médicos, enchem as cadeias e são devastadas pelos crimes e drogas em um ambiente "afamiliar".

Ocorre negligência infantil quando os responsáveis, em qualquer nível, pelas necessidades básicas da criança, deixam de cumpri-los.

$\mathrm{Na}$ sua forma mais branda pode ser encarada como uma falta de vigilância e segurança, estando exposta a maior risco de acidentes e intoxicações. Na sua forma mais grave, o paciente se apresenta com atraso de crescimento e retardamento do desenvolvimento como resultado de alimentação inadequada ou ineficaz.

"A pobreza não é igual à negligencia"

Fatores de risco são similares aos encontrados nos casos de abuso. A maioria foi indesejada e procurou-se pouca assistência no pré-natal. Os pais não parecem preocupados com o atraso. Poucos cuidados médicos e vacinas atrasadas.

Essas crianças sorriem pouco, são apáticas e retraídas quando deixadas sozinhas. Apresentam mais interesse em objetos que em pessoas. Evitam contato com os olhos e se recusam a ser tocadas ou acariciadas.

Higiene precária, roupas sujas e assaduras de fralda. A maneira de confirmar é remover a criança de seu meio e observar o crescimento quando bem alimentada.

A lei pode ser útil para mudar o comportamento. Mais eficaz em solicitar limites de segurança para medicamentos, temperatura para aquecedores de água, segurança de brinquedos e dispositivos de segurança.

\section{Abuso emocional}

Associa-se a todas as outras, embora possa ocorrer isoladamente e variar desde a desatenção até a rejeição ostensiva, expiação ou sujeição pelo terror. Por não deixar estigmas visíveis é muito difícil de se documentar.

As vítimas podem se apresentar com ansiedade crônica grave, agitação, hiperatividade, depressão ou reações psicóticas ostensivas.

Muitas são socialmente retraídas, tem problemas em se relacionar e vão mal na escola. Uma baixa auto-estima é a regra.

\section{REFERÊNCIAS}

DUBOWITZ, H.; KING, H. Violência familiar - Uma abordagem voltada para a família e a criança. Clínicas Pediátricas da América do Norte, v. 1, p. 145-155, 1995.

HELFER, R. E. Negligência com nossas crianças. Clínicas Pediátricas da América do Norte, v. 4, p. 999-1020, 1995.

JOHSON, C. F. Lesões infligidas versus lesões acidentais. Clínicas Pediátricas da América do Norte, v. 4, p. 861-885, 1990.

KINI, N.; LAZORITZ, S. Avaliação para possível abuso físico ou sexual. Clínicas Pediátricas da América do Norte, v. 1, p. 203-219, 1998.

MERTEN, D. F.; CARPENTER, B. L. M. Imagens radiológicas de lesões infligidas na síndrome de abuso de crianças. Clínicas Pediátricas da América do Norte, v. 4, p. 887-910, 1990.

PARADISE, J. E. Avaliação médica de crianças vítimas de abuso sexual. Clínicas Pediátricas da América do Norte, v. 4 , p. 911-936, 1990. 